\title{
Article \\ Network-Based Approach to Repurpose Approved Drugs for COVID-19 by Integrating GWAS and Text Mining Data
}

\author{
Shuang Liang ${ }^{1}{ }^{\oplus}$, Hui-Min Liu ${ }^{1}$, Dan-Yang Liu ${ }^{2}$, Wan-Qiang Lv ${ }^{1}$, Sheng-Ran Wang ${ }^{1}$, Jia-Chen Liu ${ }^{1}$, \\ Jonathan Greenbaum ${ }^{3}$, Hui Shen ${ }^{3}$, Hong-Mei Xiao ${ }^{1, *}$ and Hong-Wen Deng ${ }^{3, *}$
}

1 Center for System Biology, Data Sciences, and Reproductive Health, School of Basic Medical Science, Central South University, Changsha 410013, China; shliang@csu.edu.cn (S.L.); 186501014@csu.edu.cn (H.-M.L.); wqlv1990@csu.edu.cn (W.-Q.L.); 196501013@csu.edu.cn (S.-R.W.); ljch1999@csu.edu.cn (J.-C.L.)

2 Laboratory of Molecular and Statistical Genetics, College of Life Sciences, Hunan Normal University, Changsha 410013, China; danyang.liu@hunnu.edu.cn

3 Tulane Center of Biomedical Informatics and Genomics, Deming Department of Medicine, Tulane University School of Medicine, New Orleans, LA 70112, USA; jgreenb8@tulane.edu (J.G.); hshen3@tulane.edu (H.S.)

* Correspondence: hmxiao@csu.edu.cn (H.-M.X.); hdeng2@tulane.edu (H.-W.D.); Tel.: +1-504-988-1310 (H.-W.D.)

check for updates

Citation: Liang, S.; Liu, H.-M.; Liu, D.-Y.; Lv, W.-Q.; Wang, S.-R.; Liu, J.-C.; Greenbaum, J.; Shen, H.; Xiao, H.-M.; Deng, H.-W. Network-Based Approach to Repurpose Approved Drugs for COVID-19 by Integrating GWAS and Text Mining Data. Processes 2022, 10, 326. https:// doi.org/10.3390/pr10020326

Academic Editor: Alina Pyka-Pająk

Received: 13 December 2021

Accepted: 30 January 2022

Published: 8 February 2022

Publisher's Note: MDPI stays neutra with regard to jurisdictional claims in published maps and institutional affiliations.

Copyright: (C) 2022 by the authors. Licensee MDPI, Basel, Switzerland. This article is an open access article distributed under the terms and conditions of the Creative Commons Attribution (CC BY) license (https:// creativecommons.org/licenses/by/ $4.0 /)$
Abstract: The coronavirus disease 19 (COVID-19) is a global pandemic caused by severe acute respiratory syndrome coronavirus 2 (SARS-CoV-2), which has a rapidly increasing prevalence and has caused significant morbidity/mortality. Despite the availability of many vaccines that can offer widespread immunization, it is also important to reach effective treatment for COVID-19 patients. However, the development of novel drug therapeutics is usually a time-consuming and costly process, and therefore, repositioning drugs that were previously approved for other purposes could have a major impact on the fight against COVID-19. Here, we first identified lung-specific gene regulatory/interaction subnetworks (COVID-19-related genes modules) enriched for COVID-19associated genes obtained from GWAS and text mining. We then screened the targets of 220 approved drugs from DrugBank, obtained their drug-induced gene expression profiles in the LINCS database, and constructed lung-specific drug-related gene modules. By applying an integrated network-based approach to quantify the interactions of the COVID-19-related gene modules and drug-related gene modules, we prioritized 13 approved drugs (e.g., alitretinoin, clocortolone, terazosin, doconexent, and pergolide) that could potentially be repurposed for the treatment of COVID-19. These findings provide important and timely insights into alternative therapeutic options that should be further explored as COVID-19 continues to spread.

Keywords: COVID-19; fine-mapping; drug repurposing; protein-protein interaction network; proximity score

\section{Introduction}

Over the course of the past two years, a novel acute respiratory disease, coronavirus disease 2019 (COVID-19), has emerged as a global pandemic and resulted in significant loss of human life. COVID-19 is caused by severe acute respiratory syndrome coronavirus 2 (SARS-CoV-2), a positive-stranded RNA virus [1] that shares $79 \%$ of its genome sequence with severe acute respiratory syndrome coronavirus (SARS-CoV) $[2,3]$. SARS-CoV-2 is highly transmissible, and the presence of many undocumented/asymptomatic individuals has facilitated rapid viral spread [4]. Since the outbreak of the COVID-19 pandemic, SARS-CoV-2 has infected over 245 million people and led to more than 4.9 million deaths worldwide [5]. Although the majority of infected individuals do not suffer serious clinical symptoms, a notable proportion (15-30\%) of those hospitalized with COVID-19 will become severely ill and have a significant mortality risk [6]. The burden of severe COVID-19 cases 
is especially large in the elderly, as well as those with chronic diseases such as obesity, hypertension, diabetes, and cardiovascular diseases [7].

The danger of the pandemic has been exacerbated by the lack of effective therapeutics for the treatment and prevention of the disease. Several leading vaccines developed for COVID-19 are currently approved in several countries [8]; however, their efficacy to generate immunity for SARS-CoV-2 in human populations remains to be seen, as the virus continually mutates. A number of drugs have been approved or advanced into clinical trials for COVID-19, but the therapeutic effect for severe COVID-19 cases is far from ideal and requires further research. According to the COVID-19 Treatment Guidelines of America, dexamethasone and remdesivir are the most well-recommended therapeutic approaches that are currently available [9]. However, the various clinical trials of remdesivir have reported contradictory results [10]. The latest such study, the World Health Organization (WHO) solidarity trial, found that remdesivir has little or no beneficial effect in hospitalized COVID-19 patients [11]. While dexamethasone is recommended for the treatment of critically ill patients [12], this treatment could only moderately reduce mortality (summary odds ratio, 0.66). Although some treatments are effective for COVID-19 patients, each has some limitations [6]. Therefore, more effective and safer drugs are still urgently needed, as the incidence of COVID-19 continues to rapidly increase.

Drug repurposing refers to the discovery of novel indications for previously approved drugs without the need for de novo drug development [13]. It has become a promising technique for drug discovery, as it can drastically shorten the time and reduce the overall cost of therapeutic development. There are several successful examples of drug repositioning, including (1) dimethyl fumarate, originally approved for psoriasis, which was repurposed to treat multiple sclerosis, and (2) sildenafil, developed for hypertension, which was repositioned to treat erectile dysfunction [14]. Drug repositioning for COVID-19 has become a major focus of the current research in order to identify alternative therapeutic approaches that are effective in the interim as novel drugs are being developed [13]. Network-based drug repurposing approaches have been widely used to discover therapeutics for the treatment of various human diseases [15].

In this study, we performed an integrative network-based drug repurposing analysis [16] to identify previously approved drugs that may be effective for COVID-19 intervention. We identified a number of drugs that may have therapeutic efficacy in COVID-19 patients that should be followed up in clinical trials and validation experiments.

\section{Materials and Methods}

\subsection{Overview of the Computational Procedure}

Our analytical workflow to repurpose drugs for COVID-19 is composed of five steps, as shown in Figure 1. First, significant genes associated with COVID-19 were identified from previous genome-wide association studies (GWAS) [17] and through text mining in the literature (Figure 1, step 1). Second, we integrated the lung-specific transcriptional regulatory network [18] with the lung-specific human protein-protein interaction network [19] to construct a lung-specific background network (Figure 1, step 2). Third, we screened the approved drugs and their targets from DrugBank [20], along with drug-induced gene expression profiles from the Library of Integrated Cellular Signatures (LINCS) [21], to construct drug-related gene modules (Figure 1, step 3). Fourth, we determined which network modules in the lung-specific background network are enriched for COVID-19-associated genes, termed lung-specific COVID-19 gene modules (Figure 1, step 4). Similarly, we mapped drug targets/signature genes to the lung-specific background network to construct lung-specific drug-related gene modules (Figure 1, step 4). Finally, to evaluate the potential drug-induced effects on COVID-19 patients, a proximity score was calculated between the lung-specific COVID-19 gene modules and the lung-specific drug-related gene modules (Figure 1, step 5). The detailed approaches for each step are described below. 


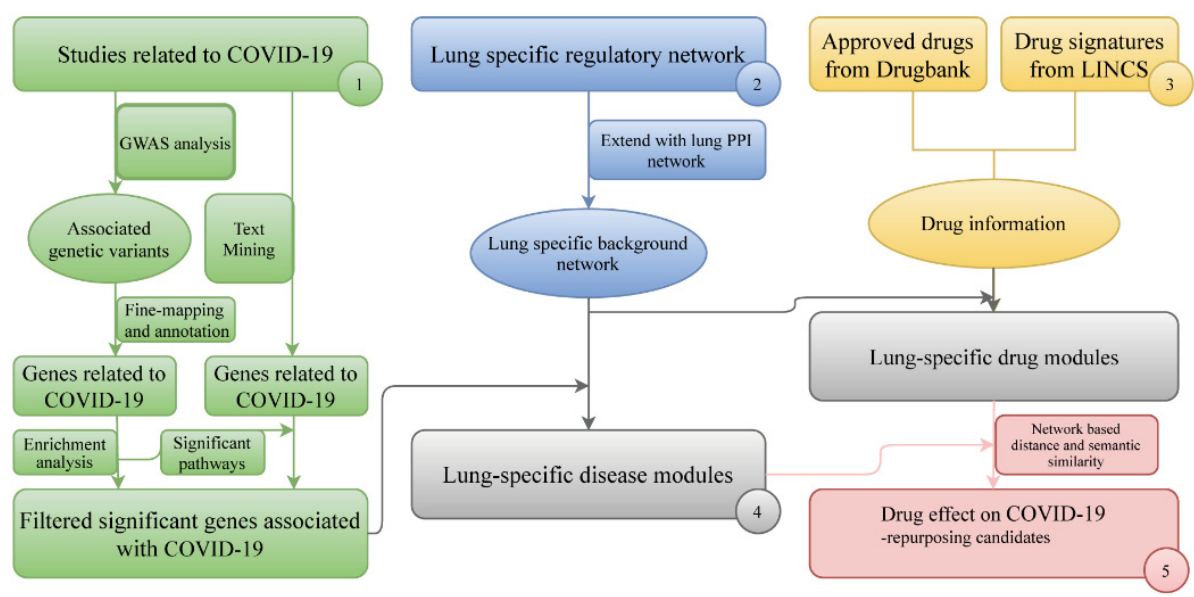

Figure 1. Schematic illustration of the computational procedure. Step 1: Significant COVID-19associated genes are identified by combining the GWAS results and literature findings, followed by a filtering step based on the gene set enrichment analysis. Step 2: A lung-specific background molecular network is constructed by integrating lung-specific transcriptional regulatory and PPI networks. Step 3: The drug information is downloaded from the DrugBank and LINCS databases. Step 4: COVID-19-related gene modules and drug-related gene modules are established using the network analysis. Step 5: To measure the drug effects, a proximity score between the drug- and COVID-19-related gene modules is computed based on the network distance and semantic similarity.

\subsection{Identification of COVID-19-Associated Genes}

The COVID-19 GWAS summary statistics were obtained from the COVID-19 Host Genetics Initiative (COVID19-hg GWAS meta-analyses round 4) [17]. The data included 6406 hospitalized COVID-19 patients (laboratory-confirmed SARS-CoV-2 infection and hospitalized for COVID-19) and 902,088 controls (everybody that was not a case). All subjects were from European ancestry. Single-nucleotide polymorphisms (SNPs) with $p$-values $<5 \times 10^{-8}$ in association analyses and without significant heterogeneity in the allelic effects between studies ( $p$-value $>0.05$ in Cochran's $Q$ test) were considered as COVID-19-associated SNPs. We used snpclip [22] to choose independent lead SNPs with a linkage disequilibrium $\mathrm{r}^{2} \leq 0.1$ and minor allele frequency $>0.01$.

The PAINTOR v3.0 fine-mapping approach [23] was used to prioritize potential causal variants by integrating the GWAS summary statistics, linkage disequilibrium structure, and functional annotations for the SNPs located at the risk loci for each trait. The fine-mapping regions were defined by selecting a window $50 \mathrm{~kb}$ upstream and downstream of each lead SNP. The linkage disequilibrium structure was provided by the 1000 Genomes Project reference panel. The functional annotations of each SNP were used to improve the accuracy of the causal variant selection. A total of 5 annotation collections (Supplementary Table S1) were used in our study. SNPs with a posterior probability of causality $>0.90$ were annotated to the corresponding genes using Ensembl Variant Effect Predictor [24]. The gene transcript boundaries were extended $110 \mathrm{~kb}$ and $40 \mathrm{~kb}$ in the upstream and downstream directions, respectively [25].

COVID-19-related genes were also selected by literature mining in PubMed and text mining of the data associated with COVID-19 in the Open Targets Platform [26]. The abstracts of the literature containing the following COVID-19-related Medical Subject Headings (MeSH) terms were downloaded from the PubMed library: 2019 novel coronavirus disease, COVID19, COVID-19 pandemic, SARS-CoV-2 infection, COVID-19 virus disease, 2019 novel coronavirus infection, 2019-nCoV infection, coronavirus disease 2019, coronavirus disease-19, 2019-nCoV disease, and COVID-19 virus infection. The tag "MeSH Major Topic" was used to limit the search. Additionally, we complemented the MeSH Major Topic search with a keyword search using the PubMed "Title/Abstract" tag. The keyword search terms were the same as the MeSH terms above. Finally, the search objects were 
limited to humans. All of the PubMed abstracts were downloaded on 20 October 2020. We extracted the genes mentioned in the downloaded PubMed abstracts with the R package pubmed.mineR [26]. In the Open Targets Platform, we performed a disease search with the keyword COVID-19 to identify the genes associated with COVID-19 (downloaded on 20 October 2020). COVID-19-related genes selected by text mining from both data sources were abbreviated as "text mining genes" in the following.

To refine the list of COVID-19-related genes, we combined GWAS genes and text mining genes using the following approach. First, we performed a gene set enrichment analysis (GSEA) of the GWAS genes by using the online tool Enrichr [27]. Second, we performed another GSEA by using both GWAS genes and text mining genes and selected those genes that were included in the "significant pathways" as the filtered COVID-19associated genes (termed COVID-19 genes). The pathways/functional terms were obtained from Biocarta, GO (Gene Ontology) biological processes, Humancyc, Kyoto Encyclopedia of Genes and Genomes (KEGG), NCI-Nature, Panther, Reactome, and WikiPathways.

\subsection{Construction of Lung-Specific Background Molecular Network}

A lung-specific background network was constructed by integrating the lung-specific transcriptional regulatory [18] and protein-protein interaction (PPI) networks. The lungspecific transcriptional regulatory network was obtained from FANTOM5 [28]. A cut-off value of 0.15 for the edge weights was used to obtain reliable interactions. This value was determined by considering the following three factors [16]: (a) there were no/few nodes in the network with a weight over $0.5,(\mathrm{~b})$ the threshold of edge weights smaller than 0.1 significantly increased the false positives, and (c) the threshold of 0.15 ensured that at least $25 \%$ of the nodes in the regulatory network were also included in the PPI network.

The lung-specific PPI network was derived from the Human Reference Interactome (HuRI) [19]. HuRI is a systematically generated human protein interactome map, which includes more than 50,000 PPIs with high biophysical quality, as measured by a yeast twohybrid ( $\mathrm{Y} 2 \mathrm{H}$ ) and verified in independent assays [19]. Based on the RNA-Seq expression profiles of the lung tissue from the Genotype-Tissue Expression (GTEx) project [29], we selected lung-related genes, which are genes with median TPM (Transcripts Per Million) values $\geq 1$ in the lung tissue. Previous studies have shown that disease-associated genes and drug-targeted genes are expressed in diseased tissues [30,31]. To detect the diseaserelated and drug-related gene modules from the lung-specific background molecular network (see Section 2.5), genes with a low expression in lung tissue (TPM $<1$ ) were removed.

Subsequently, the lung-specific regulatory and PPI networks were integrated into a lung-specific background network, which is composed of the nodes and edges of the lung-specific regulatory network and their first neighbors in the lung-specific PPI network.

\subsection{Screening of Drug Information}

All available drug information was downloaded from DrugBank [20] (version 5.1.7, published date: 2 July 2020, obtained on 3 August 2020) and LINCS [21]. We extracted the development stage, targets, and pharmacological actions for each drug. The drugs were retained for subsequent analyses if they had an approved status, were included in the lung-specific background network, and had a known pharmacological action (Figure 2). Additionally, the gene expression profiles associated with drugs (top 100 upregulated and top 100 downregulated genes) in special cell lines (HCC515: obtained from a lung tissue of carcinoma sample) were obtained from RESTful API (https://clue.io/, accessed on 10 October 2020). If the special cell lines were treated with different drug concentrations, we chose the concentrations with the highest strength parameters (distil_ss). 


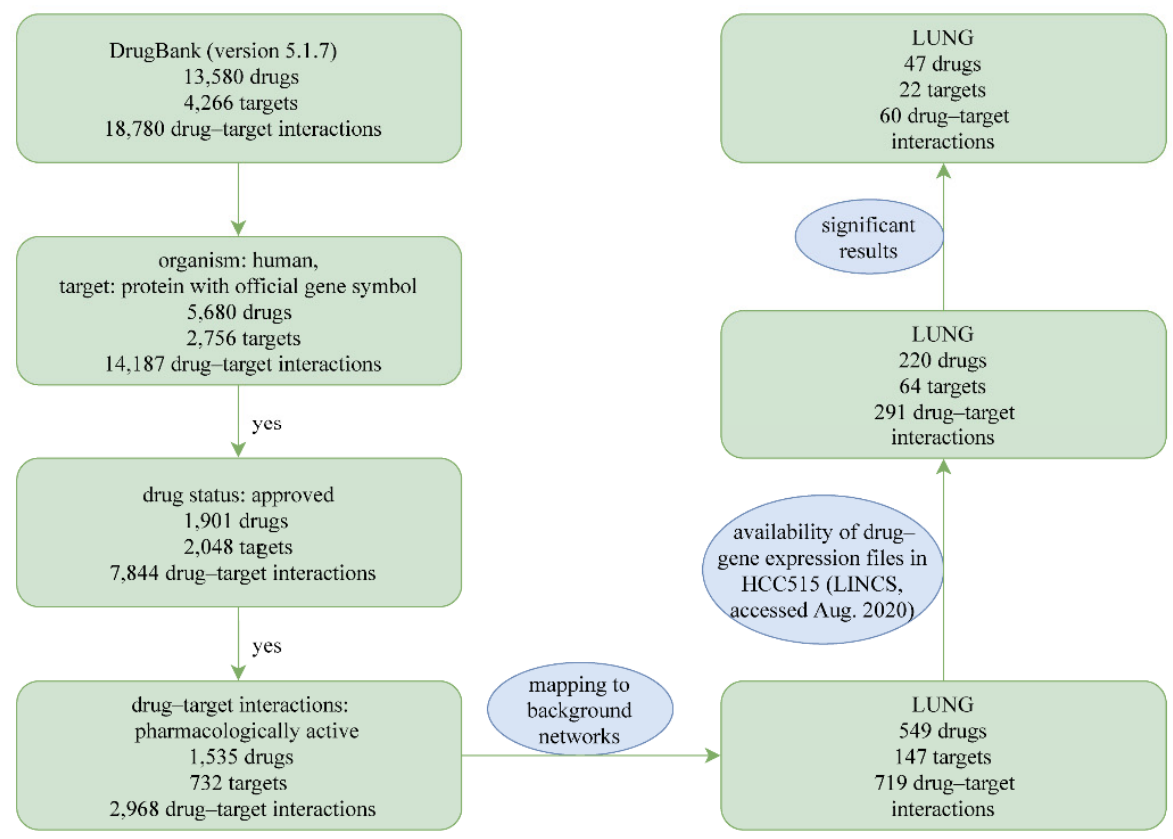

Figure 2. Overview of drug filtration. Drugs available in DrugBank (version 5.1.7) were selected according to the following steps: (1) drugs having humans as the organism, (2) drugs must be approved, (3) drug targets with a pharmacologically active status, (4) the genes for the drug targets could be mapped to the lung-specific background network, (5) the drug gene expression profiles in HCC515 (cell line) of these drugs could be retrieved from LINCS, and (6) identified drugs that have a significant proximity score.

\subsection{Identification of COVID-19-Related Gene Modules and Drug-Related Gene Modules}

COVID-19-related gene modules were detected in the lung-specific background network through the walktrap algorithm ( $\mathrm{R}$ package igraph) [32]. The walktrap algorithm detects network communities (disease modules) based on the idea that a series of short random walks tend to stay within the same network area [33]. We selected the significant COVID-19-related modules under the following criteria: (1) the module includes more than 10 genes, and (2) the module was significantly enriched for COVID-19 genes.

By mapping the drug targets and gene expression profiles associated with drugs (top 100 upregulated and top 100 downregulated genes) to the lung-specific background network, we performed a preliminary screening of the drug module genes. GO semantic similarity of the genes was calculated by using the Wang method [34] with the R package GoSemSim [35]. Drug-regulated genes that had GO semantic similarity scores $>0.5$ with drug target genes were included as the drug module genes. Finally, the drug-related gene modules consisted of drug target genes, drug module genes, and the shortest paths connecting them in the lung-specific background network.

\subsection{Evaluation of the Potential Effects of Drug Candidates on COVID-19}

The proximity score was used to evaluate the potential effects of the drug candidates on COVID-19 patients [16]. The score integrates the network-based distance and semantic similarity of the disease- and drug-related gene modules (Formula (2)). The network-based distance between the COVID-19-related gene module and the drug-related gene module was the closest distance, as defined in an earlier study [36]. As shown in Formula (1), the closest distance $d_{c}$ is the average shortest path length between the drug-related module genes and their nearest COVID-19-related module genes [36] in the lung-specific background network:

$$
\mathrm{d}_{\mathrm{c}}=\frac{1}{|T|} \sum_{t \in T} \min _{s \in S} d(s, t),
$$


where $T$ represents the drug-related module, $S$ represents the COVID-19-related module, and $d(s, t)$ is the closest distance between nodes $s$ and $t$. Normalizing this measurement with the diameter of the lung-specific background network and considering the linear transformation $1-\mathrm{d}_{\mathrm{c} \text {, norm }}$ defines a score in $[0,1]$. To evaluate the biological function similarity between the drug- and COVID-19-related modules, we calculated a similarity score in $[0,1]$ using their GO annotation (biological processes) with the R package GoSemSim [35]. Summing the $1-\mathrm{d}_{\mathrm{c}}$, norm and biological function similarity results in the final score, which takes values in $[0,2]$ :

$$
\begin{aligned}
& \text { Closest }(S, T)=\left(1-\frac{\frac{1}{|T|} \sum_{t \in T} \min _{s \in S}(t, s)}{\operatorname{Diam}(\text { network })}\right)+\text { Semantic similarity measure } \\
& =\text { Score in }[0,2]
\end{aligned}
$$

We then constructed a reference score distribution of random drug-related modules to assess the statistical significance of our results using the following strategy: (1) we selected a random drug target protein in the same degree bin as the original target, (2) random druginduced gene expression profiles were selected, maintaining the same internal distances as the original module in the lung-specific background network, and (3) random modules of drugs were constructed using the shortest paths connecting the random target and drug expression files in the lung-specific background network. We considered drugs with a score larger than $95 \%$ of the reference distribution scores to be statistically significant [16]. A higher proximity score indicates that the drug-related gene module is closer to the COVID19 gene module and/or the genes of the two modules have a higher similarity in biological functions. Therefore, drugs with higher proximity scores are more likely candidates for affecting the prognosis and outcome of COVID-19 patients.

\section{Results}

\subsection{Identification of Genes Associated with COVID-19}

GWAS has been commonly used to detect disease-associated genetic variants [37], and GWAS-associated genes have been identified as drug targets in drug repurposing for complex diseases [38]. One hundred and forty-five significant SNPs (Supplementary Table S2) associated with COVID-19 were selected from The COVID-19 Host Genetics Initiative GWAS summary statistics. The fine-mapping analysis revealed nine SNPs with a high probability of causality (rs17763537, rs75826707, rs35044562, rs951347446, rs912805253, rs1131476, rs4238034, rs6517153, and rs2229207), which were annotated to 26 genes. We further obtained 265 PubMed abstract-derived genes and 265 Open Targets Platform-derived genes for COVID-19 (Figure 3a and Supplementary Table S3). Among the 472 unique COVID-19-associated genes derived from different data sources, 164 were significantly enriched (FDR < 0.01) in 35 pathways/functional terms (Figure 4 and Supplementary Table S4). Several of these functional terms are related to viral infection, including the negative regulation of viral genome replication (GO:0045071) and negative regulation of the viral life cycle (GO:1903901). A number of other functional terms were related to the immune system, such as the chemokine-related signaling pathway (e.g., inflammation mediated by the chemokine and cytokine signaling pathways), cytokine-mediated signaling pathway (GO:0019221), and IFN-alpha signaling pathway. Chemokine signaling is essential to coordinate cell migration in health and disease and is critical to specifically govern cell positioning in space and time [39]. Cytokines play a critical role in immune function, and the abnormal activation of cytokine pathways could impair tissue homeostasis and amplify the inflammatory response. Additionally, the GSEA of the 164 genes was enriched for disease genes that were associated with infections, virus diseases, and pneumonitis (Figure 3b) based on DisGeNET [40]. 
a

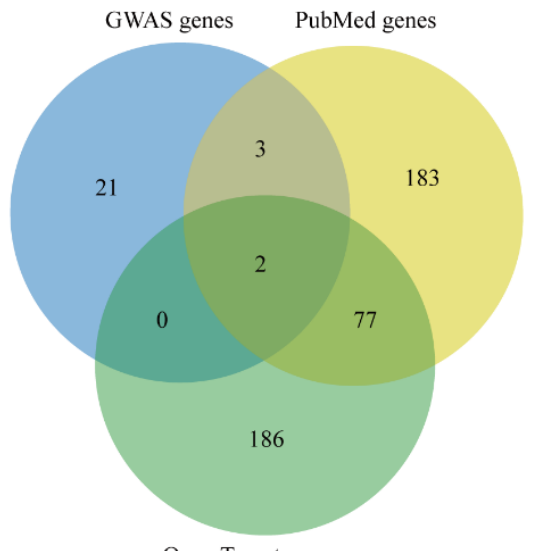

b

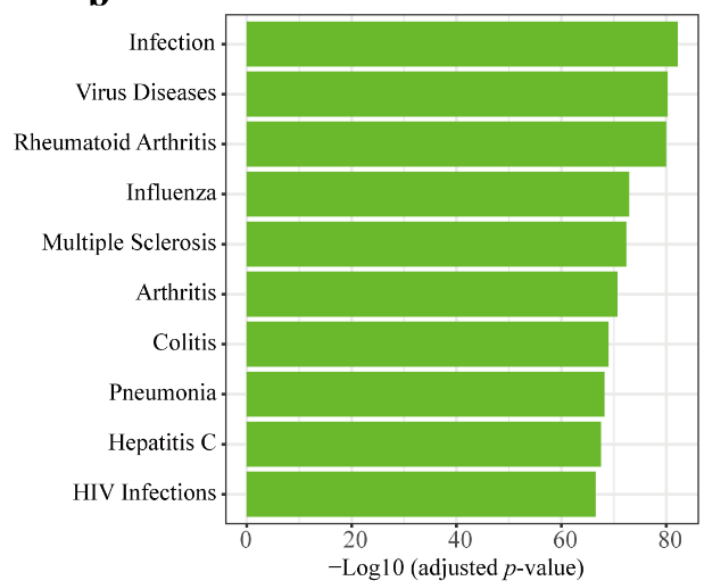

Figure 3. (a) Data source of COVID-19 genes. Venn diagram showing the overlap among the genes associated with COVID-19 identified using the GWAS (GWAS genes) and text mining methods (PubMed genes and Open Target genes). (b) Enrichment analysis of the COVID-19-associated genes using DisGeNET.

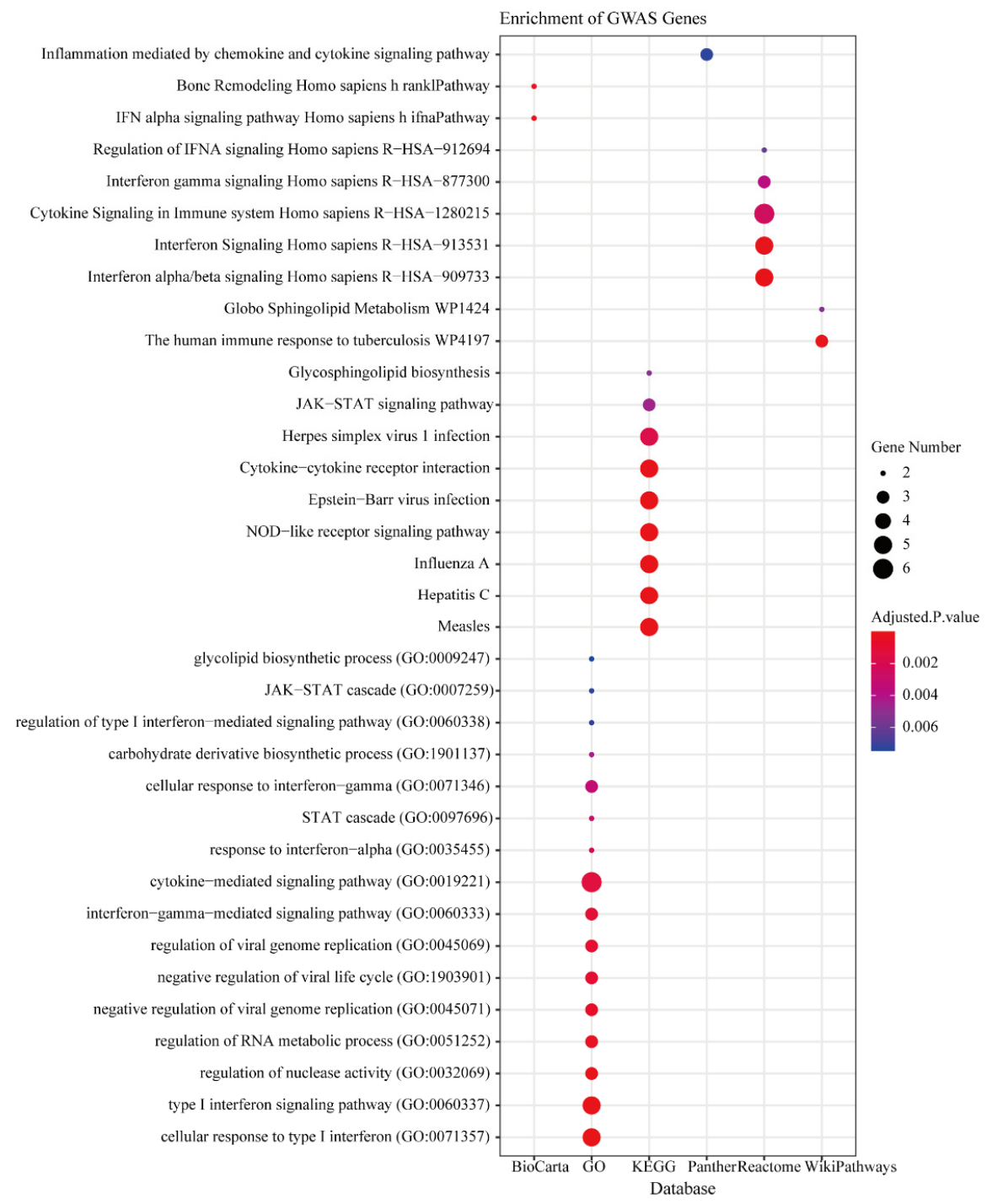

Figure 4. Results of the GSEA. Pathways and functional terms that are significantly enriched for GWAS genes. 


\subsection{Lung-Specific COVID-19-Related Gene Modules}

The lungs are the primary pathological organs of COVID-19, and pneumonia is the most common complication in hospitalized COVID-19 patients [41]. Hence, we selected the lung tissue as the most relevant tissue of COVID-19. The lung-specific background network we constructed contained 3811 nodes and 11,960 edges (Figure 5a and Supplementary Table S5), including 53 nodes that overlapped with the COVID-19 genes. Construction of the lung-specific background network could help to further identify COVID-19-related functional modules. As studies suggest, gene function is closely associated with the tissue and disease considered [42-44].

a

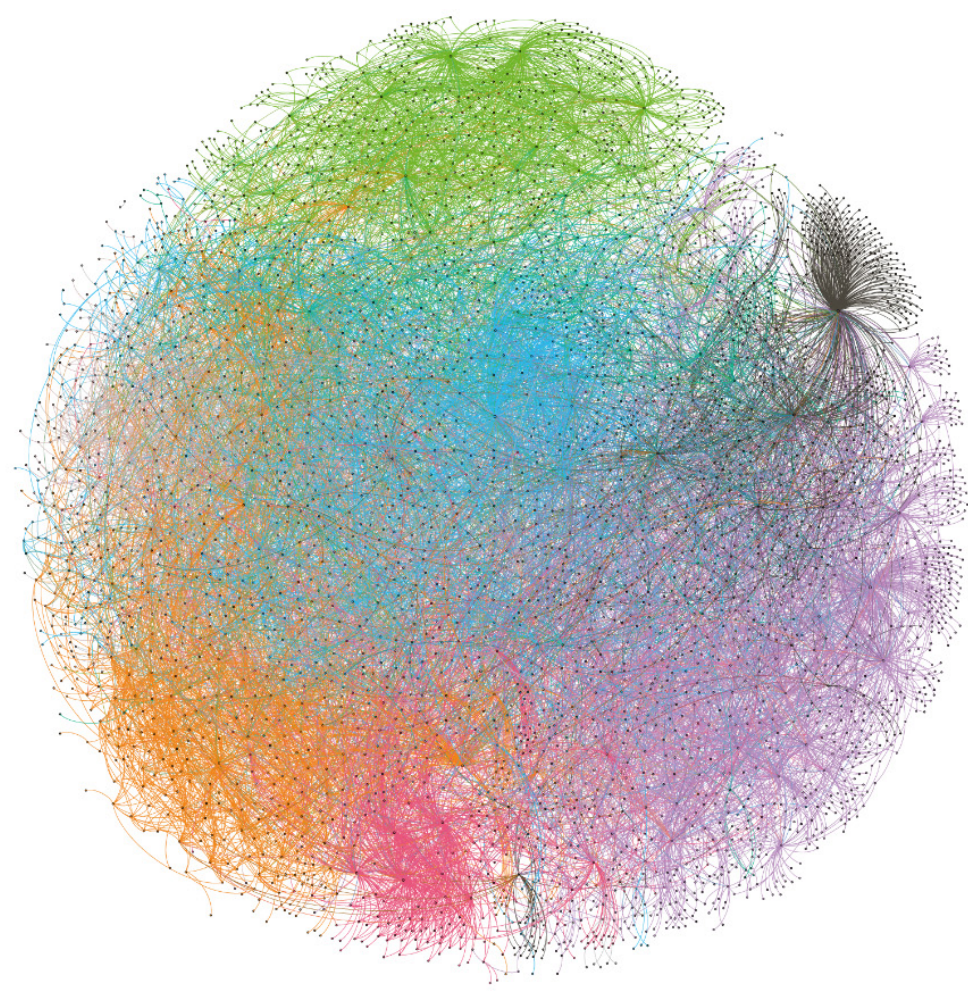

b

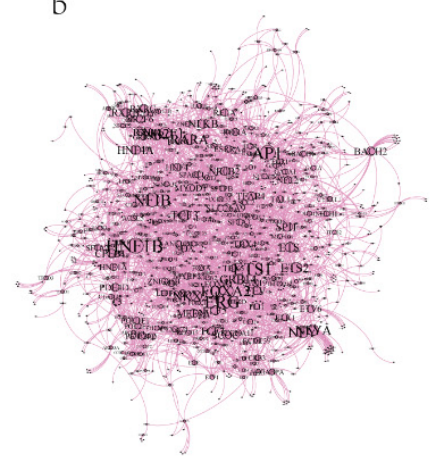

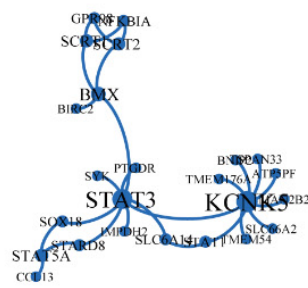

d

Figure 5. (a) The lung-specific background network. The different colors represented different modules. (b-d) The 3 COVID-19-related gene modules. Module red contains 903 genes, module blue contains 24 genes, and module green contains 46 genes. The size of the nodes is correlated with their degree centrality in the network.

Previous studies have indicated that disease genes are not scattered randomly in the human interactome but, rather, tend to cluster together and aggregate as a subnetwork (disease module) in the molecular interaction network [45-47]. In the lung-specific background network, we detected three COVID-19-related gene modules (Figure 5b-d and Supplemen- 
tary Table S6). The KEGG and Reactome enrichment analyses of these COVID-19-related gene modules highlighted a number of important biological pathways (Figure 6). The genes of module 1 were mainly enriched in pathways such as cytokine-cytokine receptor interactions, the chemokine signaling pathway, and signaling by interleukins. The genes of module 2 were mainly enriched in pathways such as the NF-kappa B signaling pathway, T17 cell differentiation, and signaling by interleukins. The genes of module 3 were mainly enriched in pathways such as complement and coagulation cascades and regulation of the complement cascade. Additionally, we observed that the module 1 genes were significantly enriched in Gene Ontology pathways related to morphogenesis and the development of lung, heart, renal, gland, and vessel (Supplementary Figure S1), including epithelial tube morphogenesis, the morphogenesis of a branching structure, heart morphogenesis, gland development, and renal system development. The results indicate that SARS-CoV-2 is damaging to multiple organs $[48,49]$, which is consistent with the outcomes observed in the clinical setting. These findings support the relevance of the identified COVID-19 gene modules, including the dysregulation or imbalance of immune cells and cytokines [50]. Targeting the host immune response may be an effective strategy for the treatment of COVID-19 [51].

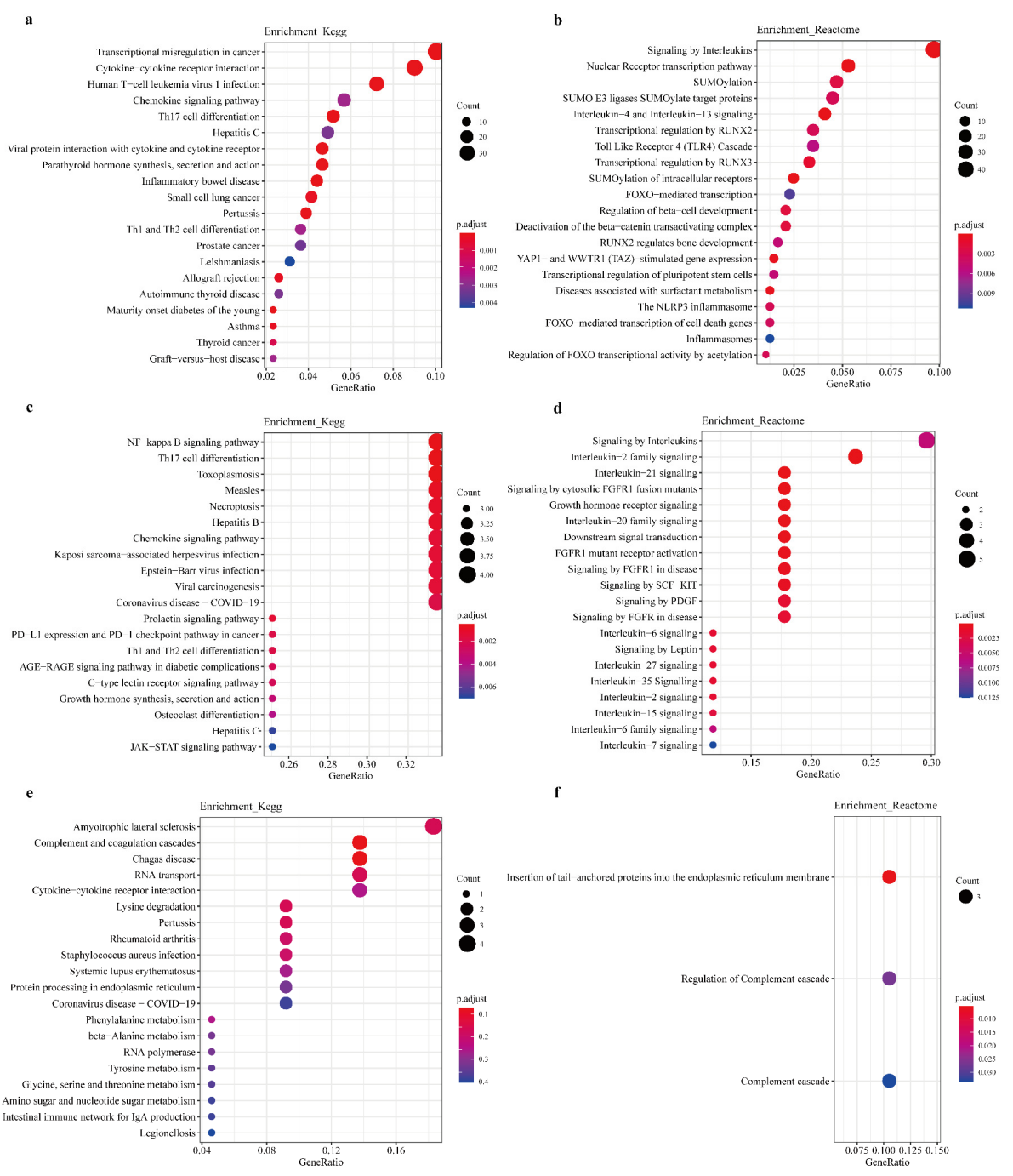

Figure 6. Functional annotations of the 3 COVID-19-related gene modules. (a) KEGG and (b) Reactome pathway enrichment analyses of the 903 genes in module 1. (c) KEGG and (d) Reactome pathway enrichment analyses of the 20 genes in module 2. (e) KEGG and (f) Reactome pathway enrichment analysis of the 46 genes in module 3. 


\subsection{Drug Repurposing}

To identify which drugs potentially act on the COVID-19-related gene modules, we filtered 220 approved drugs from DrugBank and constructed drug-related gene modules. By calculating the proximity scores [16] between the COVID-19-related gene modules and drug-related gene modules, we identified 47 drugs (Supplementary Table S7) that may have potential therapeutic value for COVID-19 patients. To select the most promising drugs that can be repurposed to treat COVID-19, further filtration and optimization were performed as follows. First, we excluded those drugs with serious side effects and contraindications for COVID-19 patients, according to the information from the DrugCentral platform [52] and DrugBank descriptions [20]. Second, among those drugs that had the same target, we excluded some drugs that had a reverse pharmacological action compared to the therapeutic drugs. For example, dexamethasone is an agonist of the NR3C1 receptor, and it has a treatment effect for severe COVID-19 patients. Hence, we removed the drugs that were antagonists/inhibitors of the NR3C1 receptor. After the filtration, we revealed 13 promising COVID-19 repurposing candidates with literature-reported antiviral or antiinflammation evidence (Table 1).

Table 1. Promising candidate drugs for COVID-19 treatment.

\begin{tabular}{cccccc}
\hline Drug IDs & Drug Name & Targets & Action & Score & Module \\
\hline DB00523 & alitretinoin & RXRB & agonist & 1.731911 & 1 \\
DB00459 & acitretin & RARG & agonist & 1.663944 & 1 \\
DB00755 & tretinoin & RARG & agonist & 1.754273 & 1 \\
DB00838 & clocortolone & NR3C1 & agonist & 1.468 & 2 \\
DB00223 & diflorasone & NR3C1 & agonist & 1.458 & 2 \\
DB00180 & flunisolide & NR3C1 & agonist & 1.468551 & 2 \\
DB13867 & fluticasone & NR3C1 & agonist & 1.45833 & 2 \\
DB00450 & droperidol & ADRA1A & antagonist & 1.65669 & 1 \\
DB01162 & terazosin & ADRA1A & antagonist & 1.660944 & 1 \\
DB00797 & tolazoline & ADRA1A & antagonist & 1.641605 & 1 \\
DB03756 & doconexent & PPARA & ligand & 1.674037 & 1 \\
DB03756 & doconexent & PPARA & ligand & 1.452954 & 2 \\
DB03756 & doconexent & PPARA & ligand & 1.470426 & 3 \\
DB01241 & gemfibrozil & PPARA & agonist & 1.640439 & 1 \\
DB01241 & gemfibrozil & PPARA & agonist & 1.444263 & 2 \\
DB01241 & gemfibrozil & PPARA & agonist & 1.464193 & 3 \\
DB01186 & pergolide & DRD2 & agonist & 1.500818 & 1 \\
\hline
\end{tabular}

\section{Discussion}

In this study, we presented an integrative network-based analysis to rapidly identify previously approved drugs that may potentially be repositioned for the treatment of COVID-19. We identified 164 COVID-19 genes and three disease-related gene modules. The GSEA of the disease genes and modules indicated that they have a high degree of correlation with immune system functionality. Finally, we found 47 drugs that might influence the outcome of COVID-19 patients and highlighted 13 of the most promising candidates.

\subsection{Retinoids}

We identified three drugs (acitretin, alitretinoin, and tretinoin) belonging to the retinoids that may benefit COVID-19 patients. Retinoids are a family of molecules related to vitamin A, including retinyl-esters, all-trans-retinal, and all-trans-retinoic acid [53]. They are commonly used to treat severe cystic acne, psoriasis, and other disorders of keratinization [20]. Many studies have indicated the immune-modulating effects of retinoids, such as modulating T-cell activation [54], increasing the expression of interleukin-2 receptor and associated interferon (IFN)- $\gamma$ levels [55]. Tretinoin and acitretin have been confirmed to inhibit SARS-CoV-2 replication through high-throughput analysis [56]. Isotretinoin, a retinoid 
derivative of vitamin A, has also been advanced into clinical trials (NCT04361422 and NCT04353180) of COVID-19. However, it is currently unclear how the retinoids inhibit SARS-CoV-2 replication. Given that SARS-CoV and Middle East respiratory syndrome coronavirus (MERS-CoV) can inhibit Type I interferon (IFN-I)-mediated antiviral responses, some articles have suggested that retinoids may stimulate the secretion and potentiate the effects of IFN-I to play an antiviral role in COVID-19 patients $[57,58]$.

\subsection{Glucocorticoids (GCs)}

We found that four GCs (clocortolone, diflorasone, flunisolide, and fluticasone) may influence the clinical outcomes of COVID-19 patients. GCs have been shown to play an important role in anti-inflammatory and immunosuppressive activities, and GCs have been widely used to treat autoimmune and inflammatory disorders [59]. Dexamethasone is a GC that has been reported to decrease mortality and shorten the hospital stays of COVID19 patients who require mechanical ventilation or nonventilated oxygen therapy [60]. At present, dexamethasone is the first and only drug that has been shown to improve the survival rate of severe COVID-19 patients. However, the early use of GCs did not decrease mortality or the need for mechanical ventilation of COVID-19 patients [61]. The success of treatment with GCs may depend on the inflammation severity. GCs might help prevent the alveolar/pulmonary damage induced by the cytokine and chemokine storm that occurs in the most critically ill patients. Several studies have indicated that severe cases may benefit from the treatment of GCs [62,63]. In addition to dexamethasone (the score of dexamethasone was less than the 95 percentile of the reference distribution scores, so we did not present it in our results), many other GCs have advanced into clinical trials, such as methylprednisolone (NCT04263402), budesonide (NCT04355637), hydrocortisone (NCT02735707), and prednisone (NCT04359511).

\subsection{Alpha-1A Adrenergic Receptor Antagonists}

We found three antagonists of the alpha-1 adrenergic receptor (droperidol, terazosin, and tolazoline) that could be repurposed to treat COVID-19 patients. The alpha-1 adrenergic receptor antagonists are used to treat hypertension and symptomatic benign prostatic hypertrophy by inhibiting smooth muscle contraction [20]. One previous study indicated that the alpha-1A adrenergic receptor $(\alpha 1-\mathrm{AR})$ is involved in the development of the cytokine storm [64]. In general, the cytokine storm is accompanied by a massive increase in catecholamines [65]. Catecholamine excess stimulates immune cells to secrete an overabundance of interleukin 6 (IL-6) and other cytokines, which could result in tissue damage [64]. Therefore, blocking the catecholamine-cytokine axis may be effective to prevent tissue damage caused by the cytokine storm. It has been reported that $\alpha 1-\mathrm{AR}$ antagonists help mitigate the cytokine storm and reduce mortality in mice [65]. Additionally, the preprinted results from a recent retrospective clinical group study revealed that $\alpha 1-\mathrm{AR}$ antagonists could regulate immune responses and prevent COVID-19 patients from developing into severe cases [66]. Based on these results, prazosin (NCT04365257) has been advanced into clinical trials for COVID-19.

\subsection{Peroxisome Proliferator-Activated Receptor Alpha (PPAR $\alpha)$-Related Drugs}

We identified two drugs (doconexent and gemfibrozil) that might have anti-inflammatory effects on COVID-19 patients via the activation of PPAR $\alpha$ PPAR $\alpha$ is a member of the peroxisome proliferator-activated receptors (PPARs), which consists of three nuclear receptor isoforms: PPAR $\alpha, \operatorname{PPAR} \delta$, and PPAR $\gamma$ [67]. Previous studies have shown that PPAR $\alpha$ can repress inflammatory activity both in vitro and in vivo [68]. For instance, PPAR $\alpha$-free mice showed a sustained inflammatory response stimulated by Leukotriene B4 (LTB4) or arachidonic acid [69]. PPAR $\alpha$ agonists could reduce the expression of acute-phase proteins such as fibrinogen, C-reactive protein, and IL-6 [70]. 


\subsection{Dopamine Receptor D2 (DRD2)-Related Drugs}

We identified pergolide, which may have a therapeutic effect on COVID-19, through the activation of DRD2. DRD2 is a common target of antipsychotic drugs and Parkinson's disease medication [71], and its $\mathrm{G}$ protein-coupled receptor inhibits adenylyl cyclase activity. Additionally, DRD2 can modulate cytokine production, activation, and proliferation in immune cells [72,73]. As a DRD2 agonist, dopamine, a potential anti-inflammatory drug, significantly inhibits the expression of proinflammatory factors secreted by M1 macrophages [74]. According to a questionnaire-based study of COVID-19 patients, those who received treatment with either amantadine or memantine (DRD2 agonist) did not present any clinical manifestations [75]. These results indicate the protective effects of adamantane by attenuating the manifestations of COVID-19 patients (the score of adamantane is less than the 95th percentile of the reference distribution scores, so we did not present it in our results). Amantadine and memantine have also displayed moderate antiviral effects in models for the bovine coronavirus, mouse hepatitis virus, human coronavirus OC43, and SARS-CoV [76]. Memantine has been reported to reduce SARS-CoV-2 virulence by decreasing ACE2 receptor expression and reducing oxidative stress and inflammation [77].

In addition to the drugs discussed above, we also found a number of other approved drugs that might be worthy to explore for treating COVID-19 patients (Supplementary Table S7). Thalidomide is used for some immunological disorders, and recent research suggests that thalidomide (NCT04273529) can be used to suppress the cytokine storm and modulate immune functions in COVID-19 patients [78]. Fostamatinib has been approved to treat chronic immune thrombocytopenia by inhibiting the spleen tyrosine kinase (SYK), and it has been reported that fostamatinib (NCT04581954) may be a potent drug for the treatment of acute lung injury (ALI) caused by SARS-CoV-2 [79]. Liothyronine is the active form of thyroxine that is used to treat thyroid hypofunction and myxedema coma [20]. Due to the protective effect in virally infected tissue and antiapoptotic action, triiodothyronine (NCT04348513) has been used to treat critically ill COVID-19 patients in a clinical trial [80]. To demonstrate the reliability of our results, we conducted a systematic review of the literature. Seventeen of the 47 drugs presented in our study are verified to have a positive effect on SARS-CoV-2 by previous studies in vitro, in vivo, or clinical trials. The associated references are presented in Supplementary Table S7.

While the network-based approach for drug repurposing has identified some potential candidates in our study, there are still a few limitations to be considered. First, the analysis was conducted using a tissue-level background network, but in the future, it may be worthwhile to explore background networks at the cell level (such as endothelium or immune cells). Second, some notable drugs were not prioritized in our results, such as dexamethasone and adamantane. This is at least partially due to the limitations of networkbased proximity and semantic similarity due to the incompleteness of the current PPI network and Gene Ontology annotation sets. Third, the SARS-CoV-2-host interactome was not considered in the analysis. This may impede the identification of some effective drugs that specifically block viral infection and suppress viral replication. Lastly, the identified repurposing candidates still require prospective validation in vitro or in vivo to determine if they are able to enhance the body's antivirus immune function.

At present, despite great effort, many COVID-19 patients have succumbed to their condition due to invalid treatment. The FDA-approved and clinically used drugs are only partially effective for COVID-19 patients. Therefore, novel therapeutic strategies still need to be explored. Previous studies have reported many different methods for drug repurposing [81]. Due to the inconsistent input data and the calculation method, different results will be obtained. However, there is no perfect approach to get the best results [82]. Our study used different methods and data from previous drug repurposing research of COVID-19, obtained some different results, and conducted literature verification. Our research represents a significant step towards identifying novel, effective therapeutic drugs. Our recommendations are immune-regulated drugs. Therefore, we suggest that experimental validation of these recommended drugs in our study should preferably be 
performed in vivo rather than in vitro (absence of the immune system). It is our hope that the drugs prioritized by this network-based computational approach will be further explored in clinical trials to validate their efficacy and effectiveness.

Supplementary Materials: The following supporting information can be downloaded at https: / / www.mdpi.com/article/10.3390/pr10020326/s1, Supplementary Figure S1: Gene Ontology enrichment pathways of genes in module 1. Supplementary Table S1: Total 52 types of annotations used with resources and descriptions. Supplementary Table S2: 145 SNPs were selected from the original GWAS data at the genome-wide significance level. Supplementary Table S3: COVID-19 related genes derived from 3 data sources. Supplementary Table S4: Significant pathways enriched for COVID-19 associated genes identified by GWAS. Supplementary Table S5: Lung-specific background network of COVID-19. Supplementary Table S6: Genes included in the 3 COVID-19 related gene modules. Supplementary Table S7: 46 approved drugs that could influence the outcome of COVID-19 patients.

Author Contributions: H.-W.D. conceived, designed, initiated, and directed the whole project. S.L., as the first author, performed the data analysis and drafted the manuscript. H.-W.D., H.-M.L., W.Q.L., S.-R.W., J.G., H.S. and H.-M.X. revised, rewrote/restructured some sections, and finalized the manuscript. D.-Y.L. and J.-C.L. contributed to the data collection and storage, text revision, and/or discussion. All authors have read and agreed to the published version of the manuscript.

Funding: HWD was partially supported by grants from the National Institutes of Health (U19AG05537301 and R01AR069055). HMX was partially supported by National Key Research \& Developmental Program of China (SQ2017YFSF080009).

Institutional Review Board Statement: Not applicable.

Conflicts of Interest: The authors declare no conflict of interest.

\section{References}

1. Romano, M.; Ruggiero, A.; Squeglia, F.; Maga, G.; Berisio, R. A Structural View of SARS-CoV-2 RNA Replication Machinery: RNA Synthesis, Proofreading and Final Capping. Cells 2020, 9, 1267. [CrossRef]

2. Xu, J.; Zhao, S.; Teng, T.; Abdalla, A.E.; Zhu, W.; Xie, L.; Wang, Y.; Guo, X. Systematic Comparison of Two Animal-to-Human Transmitted Human Coronaviruses: SARS-CoV-2 and SARS-CoV. Viruses 2020, 12, 244. [CrossRef] [PubMed]

3. Lu, R.; Zhao, X.; Li, J.; Niu, P.; Yang, B.; Wu, H.; Wang, W.; Song, H.; Huang, B.; Zhu, N.; et al. Genomic characterisation and epidemiology of 2019 novel coronavirus: Implications for virus origins and receptor binding. Lancet 2020, 395, 565-574. [CrossRef]

4. Li, R.; Pei, S.; Chen, B.; Song, Y.; Zhang, T.; Yang, W.; Shaman, J. Substantial undocumented infection facilitates the rapid dissemination of novel coronavirus (SARS-CoV-2). Science 2020, 368, 489-493. [CrossRef] [PubMed]

5. Dong, E.; Du, H.; Gardner, L. An interactive web-based dashboard to track COVID-19 in real time. Lancet Infect. Dis. 2020, 20, 533-534. [CrossRef]

6. Attaway, A.H.; Scheraga, R.G.; Bhimraj, A.; Biehl, M.; Hatipoglu, U. Severe covid-19 pneumonia: Pathogenesis and clinical management. BMJ 2021, 372, n436. [CrossRef]

7. Li, Q.; Guan, X.; Wu, P.; Wang, X.; Zhou, L.; Tong, Y.; Ren, R.; Leung, K.S.M.; Lau, E.H.Y.; Wong, J.Y.; et al. Early Transmission Dynamics in Wuhan, China, of Novel Coronavirus-Infected Pneumonia. N. Engl. J. Med. 2020, 382, 1199-1207. [CrossRef]

8. Zimmer, C.; Corum, J.; Wee, S. Coronavirus Vaccine Tracker. Available online: https://www.nytimes.com/interactive/2020 /science/ coronavirus-vaccine-tracker.html (accessed on 1 March 2021).

9. NIH. Coronavirus Disease 2019 (COVID-19) Treatment Guidelines. Available online: https:/ / www.covid19treatmentguidelines. nih.gov/ (accessed on 1 March 2021).

10. Edwards, J.K.; Cole, S.R.; Adimora, A.A. Remdesivir and COVID-19. Lancet 2020, 396, 953. [CrossRef]

11. Pan, H.; Peto, R.; Karim, Q.A.; Alejandria, M.; Henao-Restrepo, A.M.; García, C.H.; Kieny, M.-P.; Malekzadeh, R.; Murthy, S.; Preziosi, M.-P.; et al. Repurposed antiviral drugs for COVID-19-Interim WHO SOLIDARITY trial results. medRxiv 2020. [CrossRef]

12. The WHO Rapid Evidence Appraisal for COVID-19 Therapies Working Group. Association Between Administration of Systemic Corticosteroids and Mortality Among Critically Ill Patients With COVID-19: A Meta-analysis. JAMA 2020, 324, $1330-1341$. [CrossRef]

13. Zhou, Y.; Wang, F.; Tang, J.; Nussinov, R.; Cheng, F. Artificial intelligence in COVID-19 drug repurposing. Lancet Digit. Health 2020, 2, e667-e676. [CrossRef]

14. Jourdan, J.P.; Bureau, R.; Rochais, C.; Dallemagne, P. Drug repositioning: A brief overview. J. Pharm. Pharmacol. 2020, 72, 1145-1151. [CrossRef] [PubMed]

15. Alaimo, S.; Pulvirenti, A. Network-Based Drug Repositioning: Approaches, Resources, and Research Directions. Methods Mol. Biol. 2019, 1903, 97-113. [CrossRef] [PubMed] 
16. Misselbeck, K.; Parolo, S.; Lorenzini, F.; Savoca, V.; Leonardelli, L.; Bora, P.; Morine, M.J.; Mione, M.C.; Domenici, E.; Priami, C. A network-based approach to identify deregulated pathways and drug effects in metabolic syndrome. Nat. Commun. 2019, 10, 5215. [CrossRef]

17. The Covid-Host Genetics Initiative. The COVID-19 Host Genetics Initiative, a global initiative to elucidate the role of host genetic factors in susceptibility and severity of the SARS-CoV-2 virus pandemic. Eur. J. Hum. Genet. 2020, 28, 715-718. [CrossRef]

18. Marbach, D.; Lamparter, D.; Quon, G.; Kellis, M.; Kutalik, Z.; Bergmann, S. Tissue-specific regulatory circuits reveal variable modular perturbations across complex diseases. Nat. Methods 2016, 13, 366-370. [CrossRef]

19. Luck, K.; Kim, D.K.; Lambourne, L.; Spirohn, K.; Begg, B.E.; Bian, W.; Brignall, R.; Cafarelli, T.; Campos-Laborie, F.J.; Charloteaux, B.; et al. A reference map of the human binary protein interactome. Nature 2020, 580, 402-408. [CrossRef]

20. Wishart, D.S.; Feunang, Y.D.; Guo, A.C.; Lo, E.J.; Marcu, A.; Grant, J.R.; Sajed, T.; Johnson, D.; Li, C.; Sayeeda, Z.; et al. DrugBank 5.0: A major update to the DrugBank database for 2018. Nucleic Acids Res. 2018, 46, D1074-D1082. [CrossRef]

21. Subramanian, A.; Narayan, R.; Corsello, S.M.; Peck, D.D.; Natoli, T.E.; Lu, X.; Gould, J.; Davis, J.F.; Tubelli, A.A.; Asiedu, J.K.; et al A Next Generation Connectivity Map: L1000 Platform and the First 1,000,000 Profiles. Cell 2017, 171, 1437-1452. [CrossRef]

22. Machiela, M.J.; Chanock, S.J. LDlink: A web-based application for exploring population-specific haplotype structure and linking correlated alleles of possible functional variants. Bioinformatics 2015, 31, 3555-3557. [CrossRef]

23. Kichaev, G.; Roytman, M.; Johnson, R.; Eskin, E.; Lindström, S.; Kraft, P.; Pasaniuc, B. Improved methods for multi-trait fine mapping of pleiotropic risk loci. Bioinformatics 2016, 33, 248-255. [CrossRef] [PubMed]

24. McLaren, W.; Gil, L.; Hunt, S.E.; Riat, H.S.; Ritchie, G.R.; Thormann, A.; Flicek, P.; Cunningham, F. The Ensembl Variant Effect Predictor. Genome Biol. 2016, 17, 122. [CrossRef] [PubMed]

25. Segrè, A.V.; Consortium, D.; Investigators, M.; Groop, L.; Mootha, V.K.; Daly, M.J.; Altshuler, D. Common Inherited Variation in Mitochondrial Genes Is Not Enriched for Associations with Type 2 Diabetes or Related Glycemic Traits. PLoS Genet. 2010, 6 , e1001058. [CrossRef]

26. Rani, J.; Shah, A.B.; Ramachandran, S. pubmed.mineR: An R package with text-mining algorithms to analyse PubMed abstracts. J. Biosci. 2015, 40, 671-682. [CrossRef] [PubMed]

27. Kuleshov, M.V.; Jones, M.R.; Rouillard, A.D.; Fernandez, N.F.; Duan, Q.; Wang, Z.; Koplev, S.; Jenkins, S.L.; Jagodnik, K.M.; Lachmann, A.; et al. Enrichr: A comprehensive gene set enrichment analysis web server 2016 update. Nucleic Acids Res. 2016, 44, W90-W97. [CrossRef]

28. Lizio, M.; Harshbarger, J.; Shimoji, H.; Severin, J.; Kasukawa, T.; Sahin, S.; Abugessaisa, I.; Fukuda, S.; Hori, F.; Ishikawa-Kato, S.; et al. Gateways to the FANTOM5 promoter level mammalian expression atlas. Genome Biol. 2015, 16, 22. [CrossRef]

29. Aguet, F.; Brown, A.A.; Castel, S.E.; Davis, J.R.; He, Y.; Jo, B.; Mohammadi, P.; Park, Y.; Parsana, P.; Segrè, A.V.; et al. Genetic effects on gene expression across human tissues. Nature 2017, 550, 204-213. [CrossRef]

30. Kumar, V.; Sanseau, P.; Simola, D.F.; Hurle, M.R.; Agarwal, P. Systematic Analysis of Drug Targets Confirms Expression in Disease-Relevant Tissues. Sci. Rep. 2016, 6, 36205. [CrossRef]

31. Lage, K.; Hansen, N.T.; Karlberg, E.O.; Eklund, A.C.; Roque, F.S.; Donahoe, P.K.; Szallasi, Z.; Jensen, T.S.; Brunak, S. A large-scale analysis of tissue-specific pathology and gene expression of human disease genes and complexes. Proc. Natl. Acad. Sci. USA 2008, 105, 20870-20875. [CrossRef]

32. Csardi, G.; Nepusz, T. The igraph software package for complex network research. Inter J. 2006, 1695, 1-9.

33. Pons, P.; Latapy, M. Computing communities in large networks using random walks. Comput. Inf. Sci. 2005, 3733, 284-293.

34. Wang, J.Z.; Du, Z.; Payattakool, R.; Yu, P.S.; Chen, C.F. A new method to measure the semantic similarity of GO terms. Bioinformatics 2007, 23, 1274-1281. [CrossRef] [PubMed]

35. Yu, G.; Li, F.; Qin, Y.; Bo, X.; Wu, Y.; Wang, S. GOSemSim: An R package for measuring semantic similarity among GO terms and gene products. Bioinformatics 2010, 26, 976-978. [CrossRef] [PubMed]

36. Guney, E.; Menche, J.; Vidal, M.; Barábasi, A.-L. Network-based in silico drug efficacy screening. Nat. Commun. 2016, 7, 10331. [CrossRef]

37. Visscher, P.M.; Wray, N.R.; Zhang, Q.; Sklar, P.; McCarthy, M.I.; Brown, M.A.; Yang, J. 10 Years of GWAS Discovery: Biology, Function, and Translation. Am. J. Hum. Genet. 2017, 101, 5-22. [CrossRef]

38. Nabirotchkin, S.; Peluffo, A.E.; Rinaudo, P.; Yu, J.; Hajj, R.; Cohen, D. Next-generation drug repurposing using human genetics and network biology. Curr. Opin. Pharmacol. 2020, 51, 78-92. [CrossRef]

39. Legler, D.F.; Thelen, M. New insights in chemokine signaling. F1000Research 2018, 7, 95. [CrossRef]

40. Pinero, J.; Bravo, A.; Queralt-Rosinach, N.; Gutierrez-Sacristan, A.; Deu-Pons, J.; Centeno, E.; Garcia-Garcia, J.; Sanz, F.; Furlong, L.I. DisGeNET: A comprehensive platform integrating information on human disease-associated genes and variants. Nucleic Acids Res. 2017, 45, D833-D839. [CrossRef]

41. Wiersinga, W.J.; Rhodes, A.; Cheng, A.C.; Peacock, S.J.; Prescott, H.C. Pathophysiology, Transmission, Diagnosis, and Treatment of Coronavirus Disease 2019 (COVID-19): A Review. JAMA 2020, 324, 782-793. [CrossRef]

42. Greene, C.S.; Krishnan, A.; Wong, A.K.; Ricciotti, E.; Zelaya, R.A.; Himmelstein, D.S.; Zhang, R.; Hartmann, B.M.; Zaslavsky, E.; Sealfon, S.C.; et al. Understanding multicellular function and disease with human tissue-specific networks. Nat. Genet. 2015, 47, 569-576. [CrossRef]

43. Kitsak, M.; Sharma, A.; Menche, J.; Guney, E.; Ghiassian, S.D.; Loscalzo, J.; Barabási, A.-L. Tissue Specificity of Human Disease Module. Sci. Rep. 2016, 6, 35241. [CrossRef] [PubMed] 
44. Sonawane, A.R.; Platig, J.; Fagny, M.; Chen, C.Y.; Paulson, J.N.; Lopes-Ramos, C.M.; DeMeo, D.L.; Quackenbush, J.; Glass, K.; Kuijjer, M.L. Understanding Tissue-Specific Gene Regulation. Cell Rep 2017, 21, 1077-1088. [CrossRef] [PubMed]

45. Barabasi, A.L.; Gulbahce, N.; Loscalzo, J. Network medicine: A network-based approach to human disease. Nat. Rev. Genet. 2011, 12, 56-68. [CrossRef] [PubMed]

46. Gandhi, T.K.; Zhong, J.; Mathivanan, S.; Karthick, L.; Chandrika, K.N.; Mohan, S.S.; Sharma, S.; Pinkert, S.; Nagaraju, S.; Periaswamy, B.; et al. Analysis of the human protein interactome and comparison with yeast, worm and fly interaction datasets. Nat. Genet. 2006, 38, 285-293. [CrossRef] [PubMed]

47. Oti, M.; Snel, B.; Huynen, M.A.; Brunner, H.G. Predicting disease genes using protein-protein interactions. J. Med. Genet. 2006, 43, 691-698. [CrossRef] [PubMed]

48. Robba, C.; Battaglini, D.; Pelosi, P.; Rocco, P. Multiple organ dysfunction in SARS-CoV-2: MODS-CoV-2. Expert Rev. Respir. Med. 2020, 14, 865-868. [CrossRef] [PubMed]

49. Zhang, Y.; Geng, X.; Tan, Y.; Li, Q.; Xu, C.; Xu, J.; Hao, L.; Zeng, Z.; Luo, X.; Liu, F.; et al. New understanding of the damage of SARS-CoV-2 infection outside the respiratory system. Biomed. Pharmacother. 2020, 127, 110195. [CrossRef]

50. Vabret, N.; Britton, G.J.; Gruber, C.; Hegde, S.; Kim, J.; Kuksin, M.; Levantovsky, R.; Malle, L.; Moreira, A.; Park, M.D.; et al. Immunology of COVID-19: Current State of the Science. Immunity 2020, 52, 910-941. [CrossRef]

51. Yang, L.; Liu, S.; Liu, J.; Zhang, Z.; Wan, X.; Huang, B.; Chen, Y.; Zhang, Y. COVID-19: Immunopathogenesis and Immunotherapeutics. Signal Transduct. Target. Ther. 2020, 5, 128. [CrossRef]

52. Ursu, O.; Holmes, J.; Knockel, J.; Bologa, C.G.; Yang, J.J.; Mathias, S.L.; Nelson, S.J.; Oprea, T.I. DrugCentral: Online drug compendium. Nucleic Acids Res. 2017, 45, D932-D939. [CrossRef]

53. Gudas, L.J. Emerging roles for retinoids in regeneration and differentiation in normal and disease states. Biochim. Biophys. Acta, Mol. Cell Biol. Lipids 2012, 1821, 213-221. [CrossRef] [PubMed]

54. Garbe, A.; Buck, J.; Hämmerling, U. Retinoids are important cofactors in T cell activation. J. Exp. Med. 1992, 176, 109-117. [CrossRef] [PubMed]

55. Rook, A.H.; Kubin, M.; Fox, F.E.; Niu, Z.; Cassin, M.; Vowels, B.R.; Gottleib, S.L.; Vonderheid, E.C.; Lessin, S.R.; Trinchieri, G. The potential therapeutic role of interleukin-12 in cutaneous T-cell lymphoma. Ann. N. Y. Acad. Sci. 1996, 795, 310-318. [CrossRef] [PubMed]

56. Riva, L.; Yuan, S.; Yin, X.; Martin-Sancho, L.; Matsunaga, N.; Burgstaller-Muehlbacher, S.; Pache, L.; De Jesus, P.P.; Hull, M.V.; Chang, M.; et al. A Large-scale Drug Repositioning Survey for SARS-CoV-2 Antivirals. bioRxiv 2020. [CrossRef]

57. Trasino, S.E. A role for retinoids in the treatment of COVID-19? Clin. Exp. Pharmacol. Physiol. 2020, 47, 1765-1767. [CrossRef] [PubMed]

58. Sarohan, A.R. COVID-19: Endogenous Retinoic Acid Theory and Retinoic Acid Depletion Syndrome. Med. Hypotheses 2020, 144, 110250. [CrossRef]

59. Liberman, A.C.; Budziñski, M.L.; Sokn, C.; Gobbini, R.P.; Steininger, A.; Arzt, E. Regulatory and Mechanistic Actions of Glucocorticoids on T and Inflammatory Cells. Front. Endocrinol. 2018, 9, 235. [CrossRef]

60. Lammers, T.; Sofias, A.M.; van der Meel, R.; Schiffelers, R.; Storm, G.; Tacke, F.; Koschmieder, S.; Brümmendorf, T.H.; Kiessling, F.; Metselaar, J.M. Dexamethasone nanomedicines for COVID-19. Nat. Nanotechnol. 2020, 15, 622-624. [CrossRef]

61. Keller, M.J.; Kitsis, E.A.; Arora, S.; Chen, J.T.; Agarwal, S.; Ross, M.J.; Tomer, Y.; Southern, W. Effect of Systemic Glucocorticoids on Mortality or Mechanical Ventilation in Patients With COVID-19. J. Hosp. Med. 2020, 15, 489-493. [CrossRef]

62. Fadel, R.; Morrison, A.; Vahia, A.; Smith, Z.; Chaudhry, Z.; Bhargava, P.; Miller, J.; Kenney, R.; Alangaden, G.; Ramesh, M. Early Short Course Corticosteroids in Hospitalized Patients with COVID-19. Clin. Infect. Dis. 2020, 71, 2114-2120. [CrossRef]

63. Wu, C.; Chen, X.; Cai, Y.; Xia, J.a.; Zhou, X.; Xu, S.; Huang, H.; Zhang, L.; Zhou, X.; Du, C.; et al. Risk Factors Associated With Acute Respiratory Distress Syndrome and Death in Patients With Coronavirus Disease 2019 Pneumonia in Wuhan, China. JAMA Intern. Med. 2020, 180, 934-943. [CrossRef] [PubMed]

64. Konig, M.F.; Powell, M.; Staedtke, V.; Bai, R.Y.; Thomas, D.L.; Fischer, N.; Huq, S.; Khalafallah, A.M.; Koenecke, A.; Xiong, R.; et al. Preventing cytokine storm syndrome in COVID-19 using $\alpha-1$ adrenergic receptor antagonists. J. Clin. Investig. 2020, 130, 3345-3347. [CrossRef] [PubMed]

65. Staedtke, V.; Bai, R.Y.; Kim, K.; Darvas, M.; Davila, M.L.; Riggins, G.J.; Rothman, P.B.; Papadopoulos, N.; Kinzler, K.W.; Vogelstein, B.; et al. Disruption of a self-amplifying catecholamine loop reduces cytokine release syndrome. Nature 2018, 564, $273-277$. [CrossRef] [PubMed]

66. Konig, M.F.; Powell, M.; Staedtke, V.; Bai, R.-Y.; Thomas, D.L.; Fischer, N.; Huq, S.; Khalafallah, A.M.; Koenecke, A.; Xiong, R.; et al. Targeting the catecholamine-cytokine axis to prevent SARS-CoV-2 cytokine storm syndrome. medRxiv 2020. [CrossRef]

67. Berger, J.; Moller, D.E. The Mechanisms of Action of PPARs. Annu. Rev. Med. 2002, 53, 409-435. [CrossRef]

68. Youssef, J.; Badr, M. Role of Peroxisome Proliferator-Activated Receptors in Inflammation Control. J. Biomed. Biotechnol. 2004, 2004, 156-166. [CrossRef]

69. Devchand, P.R.; Keller, H.; Peters, J.M.; Vazquez, M.; Gonzalez, F.J.; Wahli, W. The PPARalpha-leukotriene B4 pathway to inflammation control. Nature 1996, 384, 39-43. [CrossRef]

70. Zambon, A.; Gervois, P.; Pauletto, P.; Fruchart, J.C.; Staels, B. Modulation of hepatic inflammatory risk markers of cardiovascular diseases by PPAR-alpha activators: Clinical and experimental evidence. Arterioscler. Thromb. Vasc. Biol. 2006, 26, 977-986. [CrossRef] 
71. Wang, S.; Che, T.; Levit, A.; Shoichet, B.K.; Wacker, D.; Roth, B.L. Structure of the D2 dopamine receptor bound to the atypical antipsychotic drug risperidone. Nature 2018, 555, 269-273. [CrossRef]

72. Beck, G.; Brinkkoetter, P.; Hanusch, C.; Schulte, J.; van Ackern, K.; van der Woude, F.J.; Yard, B.A. Clinical review: Immunomodulatory effects of dopamine in general inflammation. Crit. Care 2004, 8, 485-491. [CrossRef]

73. Torres-Rosas, R.; Yehia, G.; Pena, G.; Mishra, P.; del Rocio Thompson-Bonilla, M.; Moreno-Eutimio, M.A.; Arriaga-Pizano, L.A.; Isibasi, A.; Ulloa, L. Dopamine mediates vagal modulation of the immune system by electroacupuncture. Nat. Med. 2014, 20, 291-295. [CrossRef]

74. Han, X.; Ni, J.; Wu, Z.; Wu, J.; Li, B.; Ye, X.; Dai, J.; Chen, C.; Xue, J.; Wan, R.; et al. Myeloid-specific dopamine D2 receptor signalling controls inflammation in acute pancreatitis via inhibiting M1 macrophage. Br. J. Pharmacol. 2020, 177, 2991-3008 [CrossRef] [PubMed]

75. Rejdak, K.; Grieb, P. Adamantanes might be protective from COVID-19 in patients with neurological diseases: Multiple sclerosis, parkinsonism and cognitive impairment. Mult. Scler. Relat. Disord. 2020, 42, 102163. [CrossRef] [PubMed]

76. Cimolai, N. Potentially repurposing adamantanes for COVID-19. J. Med. Virol. 2020, 92, 531-532. [CrossRef] [PubMed]

77. Hasanagic, S.; Serdarevic, F. Potential role of memantine in the prevention and treatment of COVID-19: Its antagonism of nicotinic acetylcholine receptors and beyond. Eur. Respir. J. 2020, 56, 2001610. [CrossRef]

78. Chen, C.; Qi, F.; Shi, K.; Li, Y.; Li, J.; Chen, Y.; Pan, J.; Zhou, T.; Lin, X.; Zhang, J.; et al. Thalidomide combined with low-dose short-term glucocorticoid in the treatment of critical Coronavirus Disease 2019. Clin. Transl. Med. 2020, 10, e35. [CrossRef] [PubMed]

79. Alimova, M.; Sidhom, E.-H.; Satyam, A.; Dvela-Levitt, M.; Melanson, M.; Chamberlain, B.T.; Alper, S.L.; Santos, J.; Gutierrez, J.; Subramanian, A.; et al. A High Content Screen for Mucin-1-Reducing Compounds Identifies Fostamatinib as a Candidate for Rapid Repurposing for Acute Lung Injury during the COVID-19 pandemic. bioRxiv 2020. [CrossRef]

80. Pantos, C.; Tseti, I.; Mourouzis, I. Use of triiodothyronine to treat critically ill COVID-19 patients: A new clinical trial. Crit. Care 2020, 24, 209. [CrossRef] [PubMed]

81. Dotolo, S.; Marabotti, A.; Facchiano, A.; Tagliaferri, R. A review on drug repurposing applicable to COVID-19. Brief. Bioinform. 2021, 22, 726-741. [CrossRef] [PubMed]

82. Morselli Gysi, D.; do Valle, I.; Zitnik, M.; Ameli, A.; Gan, X.; Varol, O.; Ghiassian, S.D.; Patten, J.J.; Davey, R.A.; Loscalzo, J.; et al. Network medicine framework for identifying drug-repurposing opportunities for COVID-19. Proc. Natl. Acad. Sci. USA 2021, 118, e2025581118. [CrossRef] 